\title{
Risk factors for cardiovascular disease in obese adolescent male medical students
}

\author{
Singh M. $\mathbf{P}^{1}$, Singh $\mathbf{D}^{2}$ \\ ${ }^{1}$ Dr. Mahendra Pratap Singh, Assistant Professor, Department of Physiology, Amaltas Institute of Medical Sciences, \\ Dewas (MP), India, ${ }^{2}$ Dr. Deepti Singh, Assistant Professor, Department of Paediatrics R.K.D.F. Medical College Hospital \\ and Research Centre, Bhopal (MP), India.
}

Address for Correspondence: Dr. Mahendra Pratap Singh, Assistant Professor, Department of Physiology Amaltas Institute of Medical Sciences, Dewas (MP), India. Address-A-1, Sonal Apartment, Old Agrawal Nagar, Near Agrasen Chowk, Sapna Sangeeta Main Road, Near Prestige Investigations, Indore (M.P) India. E-mail: drsinghmp1970@gmail.com

\begin{abstract}
Objective: To find out cardiovascular risk factors in obese male medical students. Methods: Retrospective, crosssectional observational study of 411 obese male medical students. Period of study: 1 year (January 2013-January 2014). Results: Out of 411 obese male medical students $56 \%$ were hypertensive and $44 \%$ normotensive and $72 \%$ had a positive family history of Cardio Vascular Disease; 55\%were leading a sedentary lifestyle and only 44\% were exercising. About $24 \%$ of subjects were taking non-veg diet. Conclusions: Obese male medical students are at risk of developing cardiovascular diseases.
\end{abstract}

Key words: Obesity, medical students, Body Mass Index for age, hypertension.

\section{Introduction}

Obesity is an independent risk factor for cardiovascular disease. Obesity is associated with an increased risk of morbidity and mortality as well as reduced life expectancy. The last two decades of the previous century have witnessed dramatic increase in health care costs due to obesity and related issues among children and adolescents.

Obesity is a medical condition in which excess body fat accumulates to the extent that it has an adverse effect on health, leading to reduced life expectancy and/or increased health problems[1]. It is defined by Body Mass Index (BMI) and further evaluated in terms of fat distribution via the waist-hip ratio and total cardiovascular risk factors. Body Mass Index (BMI) defines people as underweight when their BMI is $<18.5$ $\mathrm{kg} / \mathrm{m}^{2}$, normal weight when BMI is between $18.5 \mathrm{~kg} / \mathrm{m}^{2}$ and $24.9 \mathrm{~kg} / \mathrm{m}^{2}$, overweight (pre-obese) when their BMI is between $25 \mathrm{~kg} / \mathrm{m}^{2}$ and $30 \mathrm{~kg} / \mathrm{m}^{2}$, and obese when it is

Manuscript received: $5^{\text {th }}$ October 2016

Reviewed: $13^{\text {th }}$ October 2016

Author Corrected: $20^{\text {th }}$ October 2016

Accepted for Publication: $28^{\text {th }}$ October 2016 greater than $30 \mathrm{~kg} / \mathrm{m}^{2}$ [1]. BMI provides a simple, convenient measurement of obesity. Nowadays Young Medical Students are very prone to develop cardiovascular risk factors simply due to -lack of exercise, junk food, extended hours of Laptop or TV viewing, and stress of studies.

This sedentary lifestyle goes a long way in developing Obesity, Hypertension and Cardiovascular diseases in later years. of life, leading to cardiovascular morbidity and mortality. Very few studies worldwide have focused on young medical students. At this juncture of their life with proper advice they can adopt a healthy lifestyle, avoid cardiovascular risk factors and be able to serve the society well.

\section{Methods}

The present study was conducted at the Department of Physiology, Index Medical College, Hospital and Research Centre, Indore for duration of one year with male medical students who were studying in Index Medical College. 
Study Design: Cross-sectional and observational study.

Study Population: Male medical students of Medical College.

Study Place: Department of Physiology, Index Medical College, Hospital \& Research Centre, Indore.

Size of the study population: Total 411 male medical students were included after obtaining their written consent.

\section{Methodology}

Each male medical student filled up a questionnaire regarding his age, diet and family history of cardiovascular disease. Body weight (to the nearest $0.5 \mathrm{~kg}$ ) standing motionless, feet $15 \mathrm{~cm}$ apart with minimum outwear (as culturally appropriate) and no footwear.

Height (to the nearest $0.5 \mathrm{~cm}$ ) with subject standing erect against a vertical surface with head in Frankfurt Plane.

Weight and height was measured to calculate Body Mass Index (BMI) by Formula- Weight in KG/(Height in Meter) ${ }^{2}$ using the BMI criteria of WHO[1,2] the body types were categorized as underweight (BMI <18.5), normal (18.5-24.9), overweight (25.0-29.9) and obese (>30).

Blood pressure was measured by Standard mercury Sphygmomanometer and classified as per the Seventh Report of the Joint National Committee[3] where Pre-hypertension is systolic BP (SBP) of 120-139 mmHg or diastolic BP (DBP) of 80-89 mmHg and Hypertension stage 1 as SBP of 140-159 or DBP of 90-99 mmHg. Subjects were informed about the study and their voluntary written consent was taken. Since the Stage 1 hypertension had only 6 subjects, the subjects of pre-hypertension and stage 1 hypertension were clubbed into a single group for appropriate statistical analysis. Data was collected, tabulated and analysed statistically.

Statistical methods- Calculations were done by methods described by J.E. Park [4]

95\% Confidence interval (CI): It is the range of 95\% confidence in any data. To calculate CI, SEP (Standard Error of proportion) is calculated as followed

$\mathrm{SEP}=\sqrt{ }(\mathrm{pq} / \mathrm{n})$

Where

$\mathrm{p}=$ Proportion of the parameter for which $95 \% \mathrm{CI}$ is to be calculated

$\mathrm{q}=$ Proportion of the rest of the parameters

$\mathrm{n}=$ Sample size

$95 \% \mathrm{CI}=\mathrm{SEP} \times 1.96 \pm \mathrm{p}$

i.e. $(\mathrm{SEP} \times 1.96 \mathrm{CI})+(\mathrm{SEP} \times 1.96 \mathrm{CI})-\mathrm{p}$

$95 \% \mathrm{CI}$ is calculated for every parameter

\section{Results}

- Out of 411 obese subjects maximum 56\% were hypertensive and 44\% were normotensive

- $57 \%$ had positive family history of Cardiovascular disease.

- $55 \%$ were leading sedentary lifestyle; and only $45 \%$ were exercising

- Maximum $76 \%$ were having vegetarian diet while only $24 \%$ were non-vegetarian. 
Table-1: Risk factors: hypertension

\begin{tabular}{|l|c|c|c|}
\hline Blood Press ure & No. & \% & $\mathbf{9 5 \%}$ CI \\
\hline Hypertension & 230 & 56 & $($ CI-0.51-0.60) \\
\hline Normotensive & 181 & 44 & $($ CI-0.39-0.48) \\
\hline Total & 411 & 100 & \\
\hline
\end{tabular}

Out of 411 Obese subjects 56\% (CI- 0.51-0.60) were hypertensive and 44\% (CI-0.39-0.48) were normotensive.

Table-2: Risk factors: positive family history (f/h) for CVD.

\begin{tabular}{|l|c|c|c|}
\hline \multicolumn{1}{|c|}{ Risk Factor } & No. & $\mathbf{\%}$ & $\mathbf{9 5 \%}$ CI \\
\hline Positive F/H & 234 & 57 & $($ CI-0.52-0.61) \\
\hline Negative F/H & 177 & 43 & $($ CI-0.38-0.47) \\
\hline Total & 411 & 100 & \\
\hline
\end{tabular}

CVD-Cardiovascular disease

Out of 411 Obese subjects 57\% (CI-0.52-0.61) were having positive F/H for CVD

Table-3: Risk factors: lifestyle

\begin{tabular}{|l|c|c|c|}
\hline \multicolumn{1}{|c|}{ Risk Factor } & No. & \% & $\mathbf{9 5 \%}$ CI \\
\hline Sedentary lifestyle & 225 & 55 & $($ CI-0.50-0.59) \\
\hline Exercising & 186 & 45 & (CI-0.40-0.49) \\
\hline Total & 411 & 100 & \\
\hline
\end{tabular}

Out of 411 Obese subjects 55\% (CI-0.50-0.59) were leading a sedentary life while only $45 \%$ (CI-0.40-0.49) were found to be exercising.

Table- 4: Risk factors: diet

\begin{tabular}{|l|c|c|c|}
\hline \multicolumn{1}{|c|}{ Risk Factor } & No. & \% & $\mathbf{9 5 \%}$ CI \\
\hline Non Veg Diet & 99 & 24 & $($ CI-0.19-0.28) \\
\hline Veg Diet & 312 & 76 & $($ CI-0.71-0.80) \\
\hline Total & 411 & 100 & \\
\hline
\end{tabular}

Out of 411 Obese subjects only24\% (CI-0.19-0.28) were on Non-veg diet and maximum $76 \%$ (CI-0.71-0.80) were vegetarian

\section{Discussion}

Our study was conducted with 411 male Medical students of Index Medical College Hospital \& Research Center, Indore (M.P.).

Table 1 shows the percentage of Hypertension in obese medical students. Hypertension was found to be present in $56 \%$ subjects and $44 \%$ were having normal blood pressure.

A similar study from Slovakia [5] found out that prevalence of Pre-Hypertension was $22.1 \%$ and prevalence of Hypertension Stage-1 was $18 \%$. These finding s are similar to our study.

Similar study from West Bank [6] found out that $26 \%$ of total students were Hypertensive. These results are less than our study; which could be due to different geographical location or, different lifestyle. In our study $55 \%$ students were leading a sedentary life while only $45 \%$ were exercising regularly. Another Study [6] found out that $56.5 \%$ students were leading sedentary life. These results are similar to our study. Similar study from Bengal [7] found out that 13\% students from study 
group were hypertensive; which is much less than our study and it can be due to life style, local eating preferences and possibly genetic make-up. A similar study from Belgaum[8]; found out that prevalence of Pre-Hypertension was $51.8 \%$ and prevalence of Stage-1 Hypertension was $6.1 \%$. These results are only a little higher than our study; mostly due to inclusion of similar age group. Study from Belgaum also found out that $70.03 \%$ students were leading sedentary life. These results are higher than our study.

A similar Indian study [9] observed that most of the students give up their sports activities and active lifestyle long before or during their school life, in their quest to pursue a medical career. They go on to lead a sedentary lifestyle with an addition of mental stress to get through the competitive medical entrance exam. These are some of the contributory factors which cannot be overlooked. A similar study [10] also observed an increasing prevalence of sustained hypertension in the obese younger age groups as compared to their lean counterparts-In our study $24 \%$ subjects were Nonvegetarian and $76 \%$ were vegetarian. In Delhi study [11] $15.2 \%$ vegetarians and 33.5\% Non-vegetarians were found to be hypertensive. This can be attributed to local food habits and genetic makeup of people. A western study[12] found out that $16 \%$ vegetarians and $31.1 \%$ Non-vegetarians were hypertensive.Another western study from Oxford [13] found out that 41.3\% of the Non-vegetarians were hypertensive These results are more than our study which can be due to Type of meat consumed and frequency of having Non-veg diet in Western population

Family history of cardiovascular risk factors- Our study underlines the significance of family history as $57 \%$ subjects had a positive family history for cardiovascular disease. This association could be due to impairment in bar reflex sensitivity in hypertension which in part is genetically determined; these findings are similar to a western study [14]. Higher levels of angiotensinogen, cortisol and $18-\mathrm{OH}$ corticosterone (seen in the offsprings of parents with high blood pressure) may also lead to abnormalities of glucocorticoid metabolism and the renin-angiotensin system as stated in a similar western study [15]. In a similar study [16] $47.79 \%$ students were leading a sedentary life. These results are less than our study. High prevalence of Hypertension in Belgaum study can be explained by the fact that a much higher percentage $(70.03 \%)$ of their students of the study group were leading a sedentary life as compared to our study group.

\section{Conclusion}

Obesity is a major health hazard all over the world. It is becoming a major health threat among both the sexes and all age groups. Substantial proportions of young medical students are prehypertensive, hypertensive and obese.

Our results highlight the necessity to institute effective prevention and health promotion programs targeting younger age groups. Medical students are not representative of the general population, therefore the studies should be extended to young adult population and investigate the presence of obesity and major cardiovascular disease risk factors and their trends over time.

Unhealthy behavioural practices are present and may progress as students advance through medical college. Developing strategies targeting these risky behaviours and determining the causative factors are necessary measures to promote healthy life style among medical students.

Modifiable cardiovascular risk behaviours are widely prevalent among medical students and increase with years spent in the medical college. Promotion of supportive environment for strengthening student-based approaches and strategic delivery of health education is essential to target these risky behaviours among our future doctors.

Funding: None; Competing interest: None stated

What is already known?- Obesity is the major cause of cardiovascular morbidity throughout the globe.

What this study adds?- Young medical students are suffering from obesity and are at risk of developing cardiovascular diseases.

Funding: Nil, Conflict of interest: None initiated, Perission from IRB: Yes

\section{References}

1. Physical status: the use and interpretation of anthropometry. Report of a WHO Expert Committee. World Health Organ Tech Rep Ser. 1995;854: $1-452$.

2. Obesity: preventing and managing the global epidemic. Report of a WHO consultation. World Health Organ Tech Rep Ser. 2000;894:i-xii, 1-253. 
3. Seventh Report of Joint National committee NIH Publication No. 04-5230’'August 2004.

4. K.Park. Epidemiology of Chronic NonCommunicable Diseases and Conditions: Obesity, Park's Textbook of Preventive and Social Medicine, 21st Edition, Banarasidas Bhanot Publishers, 2011 Feb:366-70.

5. HUZOA Z. The prevalence of obesity and hypertension among first-year students at Trnava University in Slovakia. International Journal of Medicine and Medical Sciences. 2013 Aug; 5 (8): 361-367.

6. Tayem YI, Yaseen NA, Khader WT, Abu Rajab LO, Ramahi AB, Saleh MH. Prevalence and risk factors of obesity and hypertension among students at a central university in the West Bank. Libyan J Med. 2012;7. doi: 10.3402 /ljm. v7i0.19222. Epub 2012 Oct 15.

7. P Das, M Basu, et al .Observational assessment and correlates to blood pressure of future physicians of Bengal. Nigerian journal of clinical practice 2013 Aug; 16 (4): 433-438.

8. Renu Lohitashwa, Parwati Patil. Prevalence and trends of obesity and hypertension among young Medical students- a cross-sectional study. Int J Biol Res 2013;4(4):3540-3543.

9. Verma S, Sharma D, Larson RW. School stress in India: Effects on time and daily emotions. International Journal of Behavioural Development 2006 Nov;2 6(6): $500-508$
10. Uchiyama A, Shimuzi T, Nakagawa T, TanakaT. Association of hypertension with changes in the body mass index of university students. Environmental Health and Preventive Medicine 2008 Sept; 13(5): 271-280.

11. Rustagi $\mathrm{N}$, Taneja $\mathrm{D}$, Mishra $\mathrm{P}$, Ingle $\mathrm{G}$. Cardiovascular Risk Behavior among Students of a Medical College in Delhi. Indian J Community Med. 2011 Jan;36(1):51-3. doi: 10.4103/0970-0218.80794.

12. Melby CL, Toohey ML, Cebrick J. Blood pressure and blood lipids among vegetarian, semivegetarian, and nonvegetarian African Americans. Am J Clin Nutr. 1994 Jan;59(1):103-9.

13. Appleby PN, Davey GK, Key TJ. Hypertension and blood pressure among meat eaters, fish eaters, vegetarians and vegans in EPIC-Oxford. Public Health Nutr. 2002 Oct;5(5):645-54.

14. Parmer RJ, Cervenka JH, Stone RA. Baroreflex sensitivity and heredity in essential hypertension. Circulation. 1992 Feb;85(2):497-503.

15. Watt GC, Harrap SB, Foy CJ et al. Abnormalities of glucocorticoid metabolism and the renin-angiotensin system: a four corners approach to the identification of genetic determinants of blood pressure. J Hypertense 1992; 10(5): 473-482.

16. Kevin Fernandez, Samir Anil Singru, Maya Kshirsagar, Yasmeen Pathan. Study regarding overweight/obesity among medical students of a teaching hospital in Pune, India.Medical Journal of Dr. DY Patil University2014;7(3): 279-283.

\section{How to cite this article?}

Singh M. P, Singh D. Risk factors for cardiovascular disease in obese adolescent male medical students. J PediatrRes.2016;3(12):912-916.doi:10.17511/ijpr.2016.i12.11. 